International Journal of

Emerging Multidisciplinary Research

\title{
An Introduction to the Mobile Payment Market and Trend in China
}

\author{
Guozhong $\mathbf{L i}^{1}$ \\ ${ }^{1}$ Professor at Faculty of Management and Economics, Kunming University of Science and Technology, China
}

\begin{abstract}
Background/Objectives: This research indicates the possible reasons that explain the different phenomenon between coastal provinces and less developed provinces in China. Methods/Statistical analysis: I would like to systematically investigate and analyze the cases of Alipay payment and Wechat payment (Tenpay), which are currently popular in China. Findings: Easy settlement, which has begun to spread in China, will be expanded in the world market in the future, and currencies such as paper and coins will now evolve into virtual currencies. Improvements/Applications: At the time of transaction in China, we analyzed through a case study of settlement and tried to provide suggestions by it.
\end{abstract}

\section{Index Terms}

Mobile payment, Payment market, Trend, Wechat

\footnotetext{
Corresponding author : Guozhong $\mathrm{Li}$

narin2017@kmust.edu.cn

- Manuscript received January 18, 2019.

- Revised February 21, 2019 ; Accepted March 20, 2019.

- Date of publication March 31, 2019.

(c) The Academic Society of Convergence Science Inc.

2546-1583 @ 2017 IJEMR. Personal use is permitted, but republication/redistribution requires IJEMR permission.
} 


\section{Mobile PAYMent MARKeT OF ChINA}

Mobile payment (also referred to as mobile money, mobile money transfer, and mobile wallet) generally refers to payment services operated under financial regulation and performed from or via a mobile device. Instead of paying with cash, check, or credit cards, a consumer can use a mobile phone to pay for a wide range of services and digital or hard goods [1]. Although the concept of using non-coin-based currency systems has a long history [2], it is only recently that the technology to support such systems has become widely available.

Digital payments are economically beneficial for a variety of reasons. They are faster, cheaper, and more efficient than cash or other alternatives. They can be electronically tracked, providing higher levels of transparency and security. Because many digital payments are initiated through mobile phones, they are convenient for people or merchants who may be in remote areas where bank branches may not be available. This also makes it more cost effective for banks and other payment service providers to equip both merchants and their customers with digital payment instruments. Finally, storing value electronically is typically safer than carrying physical cash.

Users can easily initiate a wide variety of transactions directly from their mobile phones, such as buying movie or airline tickets; booking a hotel room; hailing and paying for taxis; ordering and paying for food delivery; shopping for clothes; or paying their utility bills.

The capacity of digital finance to drive economic development and financial inclusion is attracting the attention of governments and regulators globally. This is unsurprising considering its potential benefits. A 2016 report from the McKinsey Global Institute estimated that digital finance could add US\$3.7 trillion to global production by 2025 , a $6 \%$ boost from current levels [3].For China, it could mean an additional US\$1.05 trillion (RMB 7.25 trillion), a 4.2\% GDP boost [4]. Digital finance can provide meaningful access to credit and other financial services to key segments of the population who were previously underserved, such as poor people, women, farmers, and owners of small and medium-sized businesses. There is now a global effort underway to increase financial inclusion, particularly for women, and the G20 has recognized the critical importance of its success. [5]

as they realized the digital payments is proving to be an effective way to create new economic opportunities.
Alipay payment and Wechat payment are the two dominant digital payment service in China. Alipay payment is a third-party online payment platform. It was launched in China in 2004 by Alibaba Group. In 2015, Alipay had 450 million monthly active users, who each spent US\$2,921 on average [6]. By 2016, Alipay was processing 175 million transactions per day, $60 \%$ of which were completed through a mobile phone. WeChat Pay is a digital wallet service incorporated into WeChat, which was provided by Tencent company. Wechat has a combined monthly active user rate of 846 million as of 2016 [7]. WeChat had 697 million users in 2015, who spent $\$ 568$ on average, although in 2016 this figure grew $168 \%$, to $\$ 1,526$ per user.

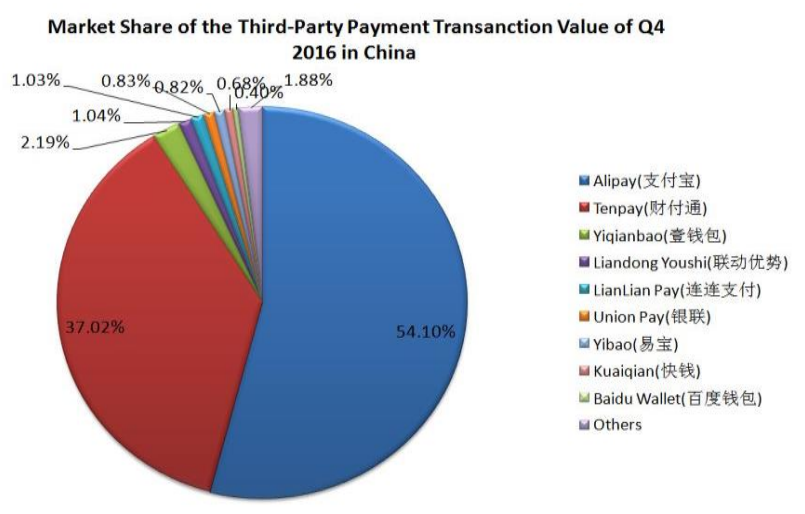

Fig. 1. The Analysis of the Market Share of the Third-Party Payment Transaction Value of Q4, 2016 in China

\section{Mobile Payment Market OF TREND}

In the business mode design of WeChat business, social platforms like WeChat serve as the important media of sharing and selling. Currently, WeChat is the mobile app with the largest user number in China and it has a coverage rate of nearly $90 \%$. On average 9 out of 20 mobile devices installed WeChat app, indicating an absolute advantage of WeChat in user coverage.

More than half of WeChat users use the app at least 10 times per day. WeChat business originates from and relies on WeChat, and WeChat's large user base offer WeChat business favorable environment for development(Table 2). 


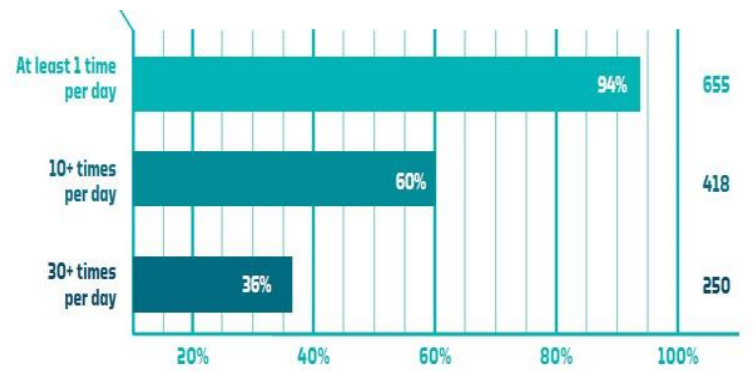

Fig. 2. \% of all users, millions of users

Among the core factors Chinese consumers took into consideration when online shopping, recommendation by friends or acquaintances ranked the second in 2016, meaning that the trust based on personal relationships has relatively significant influence on consumers' consuming behaviors. WeChat business is the business mode based on the personal relationships on WeChat and other social platforms, thus it has a solid foundation for future development(Table 3).

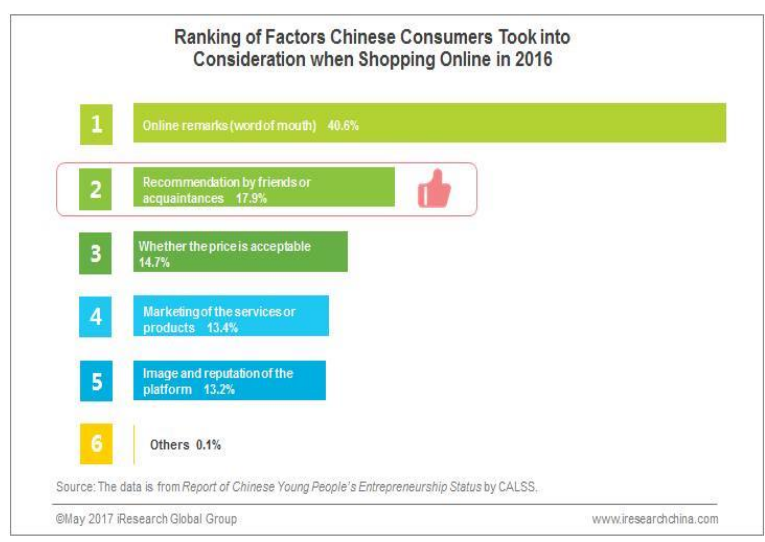

Fig. 3. Rankings of Factors Chinese Consumers Took into Consideration when Shopping Online in 2016

Unsurprisingly, Alipay users in eastern coastal provinces, including Shanghai, Beijing, and Zhejiang, spend more annually on average than the lesspopulated western provinces. Yet, the percentage of Alipay transactions completed by mobile phone is markedly higher in the less developed provinces like Guizhou, Gansu, and Shanxi. In fact, in Tibet, over $83 \%$ of digital payments were completed on a mobile phone [8]. Although data is not readily available, it is likely that household computer ownership in lessdeveloped provinces would be lower than the country as a whole, increasing the importance of, and reliance on, mobile payments for financial inclusion.

Digital payments are also very inexpensive for both merchants and users. For merchants, accepting a digital payment through Alipay or Tencent costs on average $0.6 \%$ of the value of the transaction, as compared to the typical credit card fee that can be up to $1 \%$ in China, depending on the merchant.

The scope of its digital payments ecosystems makes China an ideal case study for other countries as they consider various strategies to promote the transition from cash to digital payments and advance financial inclusion. Many factors enabled the development of these ecosystems in China. However the factors that are most relevant for potential application elsewhere can be grouped into three broad categories:

1) Effective Business Strategies for the Private Sector; 2) Supportive Regulation and Policy for Governments; and 3) Security Considerations for the Payment Providers and Governments.

\section{MOBILE PAYMENT CASES IN CHINA}

The rapid growth of social networks and ecommerce platforms has transformed the way people communicate and transact around the world. Integrating digital payments into these growing networks and platforms has presented vast opportunities to drive economic opportunity, financial inclusion, transparency, security, and growth. In practically all countries individuals, businesses, and policymakers are recognizing these opportunities and acting on them, but perhaps nowhere more so than in China.

\section{A. Case 1}

Kaiyu Ma runs a small store selling used clothing on Taobao. She says this is a great way to earn money on the side while she looks after her young daughter. Ma's situation is not unique. At a

micro level, digital payment services allow individuals to improve their own or their family's lives. At a macro level, digital payment services have the potential to dramatically improve living standards for large sections of the population, especially in developing countries, through increased transparency, security, cost savings, and financial inclusion, particularly for women.

As a young mother in the city of Ordos in Inner Mongolia, Northern China, she lives far away from the hustle and bustle of China's major cities, but has still managed to find a place in China's growing digital ecosystem, which is continuing to expand further into regional and rural areas of China.

She feels these convenient services indispensable for many of her daily activities. She uses Alibaba's 
Taobao and Tmall e-commerce platforms to shop for her 18-month old daughter, often ordering from merchants located a considerable distance from Ordos and paying with Alipay. Digital payment services are critical not just for the way she shops, but also to the way she earns money every month. A cottage industry consisting of young mothers selling clothing, accessories, shoes, and bags online has sprung up in her city as residents seek new ways of earning additional income.

Ordos was once considered an example of China's "Ghost Cities," a term used to describe those cities constructed to increase economic output in relatively low-populated, underdeveloped sections of the country. The area around Ordos is heavily reliant on coal production, which has been hit hard by the slowdown in China's energy sector. Digital finance has helped these micro and small online merchants thrive, cushioning the economic impact of the energy slowdown.

Ma is part of this group. She runs a small store selling used clothing on Taobao, Alibaba's consumer-to-consumer e-commerce platform. She says this is a great way to earn money on the side while she looks after her young daughter. It allows her to be both a mother and a provider.

Ma's situation is not unique. Every day across China, millions of consumers and businesses use digital payment services for social and commercial uses. At a micro level, digital payment services allow individuals to improve their own or their family's lives. At a macro level, digital payment services have the potential to dramatically improve living standards for large sections of the population, especially in developing countries, through increased transparency, security, cost savings, and financial inclusion, particularly for women.

\section{B. Case 2}

Wang Qi is a 23-year-old hair stylist from Chengdu. He spent a lot of time on the roadside. Wang Qi also became famous in China's increasingly competitive beauty market, including working hard and becoming a high-class man about 15 degrees a week.

Wang Qi started building a cyber network of followers, customers, and so on, using Witchat, China's famous mobile messenger, to market and grow its business. He shares his client's hair cut photos through his wi-chat, then informs people in advance where he is next, and communicates directly with the client. He started receiving follow-up calls and inquiries from new customers in many other cities throughout China through the Whitch network and began traveling all over China to serve the new customers. Wang Qi has become very famous and has 5,000 followers in his chat, which is the most frequently accepted non-commercial account.

Wang Qi travels and uses Whitch not only for networking but also for payments. This is a wichat settlement that is used universally by Chinese. Wang Qi is often on business trips several times at a time, but this means that if you cut your hair many times, you might have to carry a considerable amount of cash with you. The shift to using digital wallets was even more secure because he had a small amount of cash in addition to his practical use of paying anywhere he cut his hair.

Whitch is an important part of the Wang Qi business. But it's a more important part of his life. Wang Qi's father was previously diagnosed with cancer, but his condition deteriorated rapidly in 2015 and he needed immediate hospital care. Wang Qi and his family each time they cut their hair, they made some savings by charging RMB 200 (approximately \$29) but because of the high cost of treatment for their father and they had to compensate for a considerable amount of money.

In an attempt to gather funds, Wang posted a message on his WeChat asking his hundreds of friends and followers for any financial support they were able to provide to help pay for the treatment. Donations quickly poured in. Thanks to the instantaneous nature of WeChat payments, Wang Qi raised nearly 20,000 RMB (US\$2,900) which he used the same day to pay for his father's treatment.

Wang Qi was able to use the social engagement and trust that he had established with his followers on the WeChat network to address a financial need that he had in his life. For a country so large and so geographically diverse, many people rely on social networks for marketing, sales, or even, in the case of Wang Qi, a family emergency.

\section{CONCLUSIONS}

Based on various sources of research report, this research illustrates the possible reasons that incorporate digital payments into existing services and unlocked economic opportunities for hundreds of millions of users $[9,10]$.

By looking at China's most far-reaching applications - WeChat and Alipay, we explore their role in the development of one of the world's largest and most sophisticated digital payments ecosystems. There have been many aspects that brings significant experiences to world economy. A key overarching issue in payments (both traditional and digital) is trust 
and convenience. Smartphone based mobile social networking service is an appropriate platform where payor and payee could obtain trust between each other and trust in the security of the payment mechanism, the regulatory environment for consumer protection and recourse, and a belief that the method is beneficial.

The groups with low income are able to purchase financial products with great ease, which would drive more consumers to consider long term investment.

The Red Pocket Activity in 2016 changed people's habit for money transfer, making a large amount of money flow among visual accounts.

Small and medium enterprises are able to acquire financial support from mobile payment service providers with great ease

\section{REFERENCES}

[1] https://en.wikipedia.org/wiki/Mobile_payment.

[2] Hollow, M. (2016). Pre-1900 utopian visions of the 'cashless society'. In The Book of Payments (pp. 13-22). Palgrave Macmillan, London.

[3] Russell, J. (2016). Ant Financial, the Alibaba affiliate that operates Alipay, raises $\$ 4.5 \mathrm{~B}$ at a $\$ 60$ B valuation. TechCrunch. 2016.

https://techcrunch. com/2016/04/25/ant-financial-the-alibabaaffiliate-that-operates-alipayraises-4-5b-at-a-60b-valuation.

[4] McKinsey Global Institute(2016). Digital Finance for All: Powering Inclusive Growth in Emerging Economies.

[5] Barnett, S. G20 Governance of Digitalization, 1999-2017.

[6] http://www.g20.utoronto.ca/summits/2016hangzhou.html

[7] Tencent Holdings(2016). Tencent Announces 2016 Third Quarter Results, http://www.tencent.com/en-us/content/ir/ news/ 2016/attachments/20161116.pdf

[8] Global Partnership for Financial Inclusion(2016). China Priorities Paper, G20 China, http://www.gpfi.org/sites/ default/files/documents/Global\%20Partnership\%20for\%20Fi nancial\%20Inclusion\%20\%28GPFI\%29\%20China\%202016 $\% 20$ Priorities\%20Paper.pdf

[9] Park, S. T., Im, H., \& Noh, K. S. (2016). A study on factors affecting the adoption of LTE mobile communication service: The case of South Korea. Wireless Personal Communications, 86(1), 217-237.

[10] Li, G., \& Park, S. (2017). A Study on Patent Valuation Factors. International Journal of Emerging Multidisciplinary Research, 1(2), 15-21 [DOI: 10.22662/IJEMR.2017.1.2.015]. 